\title{
STRUCTURES AND PATHS FOR THE EXPLORATION OF LANDSCAPE - CULTURAL MOSAIC
}

\author{
Mario Taverna \\ Livio C. Piccinini \\ Ting Fa Margherita Chang \\ Luca Iseppi \\ Department of Civil Engineering and Architecture, \\ Udine University, Italy
}

\begin{abstract}
The main aim of this paper is to highlight the evolution of urban and peri-urban networks in view of their use by dwellers and visitors. It considers the knowledge as a part of a hidden permanent education form, and as a prerequisite for full enjoyment of available culture, sport and health facilities. Although, the objectives of the inhabitants and tourists are very different, their basic structural needs and the underlying methodology have common characteristics. In this prospective, the central element is the ability to build networks that connect the nodes of interest, which are functional (services at various levels), cultural (historical and artistic emerging features), and leisure (dedicated sport facilities and locations). Furthermore, the paper investigates the paths and times of networks connections, providing particular attention to multipurpose trips consistence of either dwellers or tourists. Keywords: Central place theory, Depth first, Hamiltonian paths in tourism, Smart city, Width first
\end{abstract}

\section{Central Place and Reticular theories}

To analyze the territorial networks, the content of their nodes and hierarchies must be rethought. It is useful to start from Christaller's theory of Central Places, which, in its many details and changes, is the cornerstone for any analysis of spatial interdependencies $([7][1])^{6}$. However, the fundamental hypothesis is the most controversial: in the hierarchy of central places it is assumed that the location of higher rank provides not only its own functions, but also all the functions proper to lower rank localities.

When the development and the evolution of use of landscape-cultural systems are studied, both the creation and the loss of central functions gain importance. Central places are vulnerable to the loss of core function. Progress in media and technologies reduces the need of physical movements, while new specialized core functionalities arise (dedicated shops, offices, services) so that a certain trade off is preserved.

Mobility has allowed the establishment of shopping centers of vast area. The tourist equivalent may consist of regional parks or museums in vast area, and thematic routes ${ }^{7}$.

The inaccessibility of the city to private cars let central shops become a luxury

\footnotetext{
${ }^{6}$ We refer also to [18] Section 1, where there is a summary of the evolution of the theory.

${ }^{7}$ Celebrated Italian itineraries are related to the exploration of Venetian villas, and is catching on the route of Via Francigena.
} 
item. Only personal services require the physical coupling manufacturer-user, but the territorial balance moves through thick and thin. For example, the invention of the safety razor (King Gillette) has made the barber meaningless in daily life, women's work gave rise to the role of babysitting and other analogues $\left(\right.$ dog sitter, badante ${ }^{8}$ ). Sports are still opportunities for physical exchange, but viewers are already not necessarily present; the reverse movement to make the vision and the roar of the audience is embryonic 9

One of the most convincing explanations for Christaller's theory is Behavioural Approach, which explains the presence of different rank services as a strategy implemented by the suppliers to meet the needs of customers (the multipurpose trips $^{10}$ ). The consumers are interested in maximizing both profit and satisfaction achieving economies of scale during intercourse with the services and trade: and the most popular good are leisure activities, as recognized in economics for the first time by Becker [2]. It is important to note that even in the very enjoyment of leisure time a hierarchy of options is generated, as it is well known to travel and event organizers.

The reticular theory [13] states that an intermediate centers may exist even if it provides only some of the functions of higher degree, provided that it lies in a network with others and shares functions (e.g. health versus education). Nonetheless Christaller's assumption cannot be ignored. This trend is reflected in the construction of edge cities [9]. Edge cities are artificial structures that provide a vast expanse of offices linked to houses and commercial facilities, therefore "represent" real cities with their duties and inhabitants. It is not clear where those who provide for lower functions should reside. The key assumptions of Christaller are violated on the social ground [15], even if it can be resolved by commuting (as is the case in actual experience). In other cases solution is some form of apartheid as it has always occurred e.g. on cruise ships. In the worlds of tourism, sport, spa and art, special purpose cities that correspond to this model have been created from scratch or as a transformation of existing authentic kernels. It is interesting Calvino's observation ${ }^{11}$ : in the entertainment towns, at the time of full operation, the high-level services typical of the city coexist with the "amusement park" exhibition, but out of season services are inactivated leaving only the "booths".

\section{Spatial aggregation of services and trade}

It is useful to distinguish the types of services needed by the various users. There are instrumental services such as parking or public transport. Then there

\footnotetext{
${ }^{8}$ An Italian word that means "looking about..."; some form of personal non qualified nurse.

${ }^{9}$ The case of the stadium of Trieste, where to compensate for the lack of spectators blow-ups of a hypothetical public in natural measure were posted, is still an isolated incident, but current technology would allow a projection of live scenes visible from the field, as indeed occurs with big screens.

${ }^{10}$ See e.g. Herbert and Thomas [10], 252-262.

${ }^{11}$ See in [4] the city of Sophronia, fourth of the thin cities.
} 
are the main sectors of structured services: administration, health, education; later we go down to less structured services such as personal services. In business the traditional market survives in many places, especially for fresh food, but there is a tendency to concentrate at the expense of the neighborhood groceries. Personal services (and also bar and pizzeria) are generally distributed throughout the territory, including the outskirts, in order to satisfy a client who usually resorts to soft mobility. The newspaper kiosk, the baker and the neighborhood store fit into this frame and tend to save their monopolistic position, while for other types it clicks Hotelling's paradox [11], when many providers of the same service are placed close to each others in order to be in direct contact with competitors (and also to benefit from some economies of scale). Anyhow, the proximity of suppliers of different goods is essential in the context of multipurpose trips. Even specialized centers such as hypermarkets and outlets are forced to obey the principle of function totality of Christaller. It is then obvious that as the service attraction radius increases the problem of instrumental services becomes stringent. This is one of the essential points for the great services, including hospitals and universities, sport complexes, historic centers of cities.

When it is possible the question is whether they should be accessible from outside or inside the city. Hinge solutions proved to be adequate, provided that they are accessible also from the inner city by frequent public transport, otherwise the city itself is disconnected from the services that are nominally assigned, so the role of the center of the second or third level actually is in doubt. The hospitals are sometimes isolated kernels of edge cities, although spontaneous and less structured. It almost seems that the planner wants to impose the strong sign of the new structure: it is easy to think of the hospitals of Siena and Trieste, impressive on the hills, and of the very University of Trieste in its dominant position on the gulf, although poorly connected with the city and with the central train station. Even industrial centers have resulted in towns, sometimes aesthetically valid, such as Montecatini in Ferrara, the complexes of Torviscosa (Udine) and Campione del Garda (Brescia), or the Stucky Mill on the Giudecca (Venice). The monumental buildings of the new architectural technologies have brilliantly reused degraded and interstitial areas, giving rise to new complexes integrated in themselves, even if disconnected from the surroundings. In this case mosaic tiles become increasingly large and coherent, combined with minute and organic weaving.

The competition model of Sylos Labini ${ }^{12}$ leads to evolutionary considerations. Prior to globalization, every location offered a complete package of services, even if the use basins were inefficient; at an intermediate stage it prevailed medium size, which, still offering a satisfactory coverage, dismissed the minor

\footnotetext{
${ }^{12}$ See Sylos Labini [17] for the basic idea, [15] for a specific analysis.
} 
centers (e.g. base hospitals outside the capital cities ${ }^{13}$ ) that were no longer economic. With the further globalization, when only the hub centers have the highest services, new small and specialized structures distributed in the territory will arise. That assumes, of course, a lot of information, coordination and high accessibility. This is one of the facets of edge cities, seen instead as a phenomenon of dual reticular dissemination: a sparse network of qualified emerging marks usually highly ambitions and expensive.

\section{Access and use of central places}

How to organize the exploration of a network starting from one of its nodes? Refering to the models of computer science ${ }^{14}$. There are two basic models, with different characteristics. The first model is the exploration in width ("width first"), that examines at first all the next nodes and goes further only after having completed the local analysis. The second model is the exploration in depth ("depth first"), and consists of looking for a new node starting from the last one, as long as this is possible, going back only as much as it is needed to find other sets of new nodes. The first model is typical of those who arrive in the parking area where they will return: they wish to do all the jobs that are readily available. The car park, or the bus stop, are all the more attractive as the location meets the multipurpose trip, provided that the sum of the times of the individual tasks is compatible with the total time available. The process "depth first" is suitable for those multipurpose trips that do not wish to go back to the starting point. In the case of soft mobility theoretically one may always be in a situation of this kind, provided that he can find some suitable stop of public transport, or goes back home by a different path. Sometimes it is possible an intermediate model of "multipurpose islands"15: there is firstly a very sparse network based on some fundamental interchange points (parking, public transports) and it is reachable with one of the previous two methods, while the complete fulfillment of the functions is achieved in turn starting from each multipurpose island with the technique of "width first". Sometimes the passage between two islands not too far away takes place with the technique of "depth first" ${ }^{16}$. Accessibility in the modern city and its suburban neighborhoods reflects the latter frame of reference, since one no longer moves within the territorial fabric, but jumps from one node to another, for instance toll, parking lots or public transport; only soft mobility allows a completely free choice, although time constraints limit its range.

In the systematic exploration of an area, Hamiltonian paths might be recalled;

\footnotetext{
${ }^{13}$ But also many sports facilities lack the critical dimension, such as ski lifts in isolated small ski resorts.

${ }^{14}$ Specific algorithms has been developed after the advent of automatic computation, because computers do not have eyes, so there is no graphical intuition. A famous reference manual is [8], in particular we remind the chapter about Advanced data structures, pp. 469-484.

${ }^{15}$ In addition to the aforementioned [10] we taken into account Berry et al. [3].

${ }^{16}$ A detailed analysis of the three models from the operational point of view was made in by the authors in [16].
} 
these paths make a cycle tapping all nodes only once, as is the dream of tourists who want to visit a place quickly. The problem becomes even more complex when there is a search of optimality of time and costs, thus entering in the classic traveling salesman problem. It is noted that the Hamiltonian path contrasts with the general functional structure of public communications networks, and therefore it must be customized, either by private means, where this is feasible (periurban area) or through structured travel, as is the case with the transport of tourists, where many parking places are strategically connected. The principle of non-repetitive sequence also acts on the wider territory: examples are the great chains of interesting places next to each other such as San Quirico d'Orcia, Pienza, Montepulciano (Siena) or Pitigliano, Sovana, Sorano (Grosseto) with the eventual reunification in the important tourist center of Orvieto (Terni). In case of paths with multiple sequential objectives a good information structure about time and manner of access is needed, more relevant the more far apart the sites are located.

\section{The simplification of the central locations}

When the services that form a multipurpose system begin to vanish centrality can disappear. For simplicity the case of two services is considered. Two locations that contain only one of the services might not be integrated if there is a third location (the capital), which continues to offer them both. Analyzing this process, in order to avoid computational complexity, Manhattan metric in used; it applies to an orthogonal mesh of roads, not allowing diagonal paths; anyhow this choice is justified in the modern urban fabric, and it is not unrealistic even at regional level. In Figures 1 and 2 two different metric assumptions are submitted, while the general hypotheses remain the same: the two locations subject to lose centrality are A and B, and the persistent main town is C. It is assumed that the population is evenly distributed. It is supposed that originally $\mathrm{A}, \mathrm{B}$ and $\mathrm{C}$ are capable of providing separately each of the products/services $\mathrm{P}$ and Q. The figures show two different geometries: A and B near or distant. Figures labelled sub a) show the original three areas of influence. The geographical distribution is balanced, and therefore the three distributors of services could be economically viable $(28,28,44$ in the first case; $27,27,46$ in the second case). If the sustainable basin becomes more demanding (i.e. larger), one of three suppliers will exit the market. Suppose that at this point $\mathrm{P}$ is supplied only from $\mathrm{A}$ and $\mathrm{C}$; the new attraction basin is that shown in figures labelled sub b). In this case there is a good balance ( 48 for A, 52 for C; 42 for A, 58 for $\mathrm{C}$ respectively). Suppose now that the similar process occurs for $\mathrm{Q}$, and that it is available only in B and C. The basin of B (symmetric) would be balanced and sustainable. 


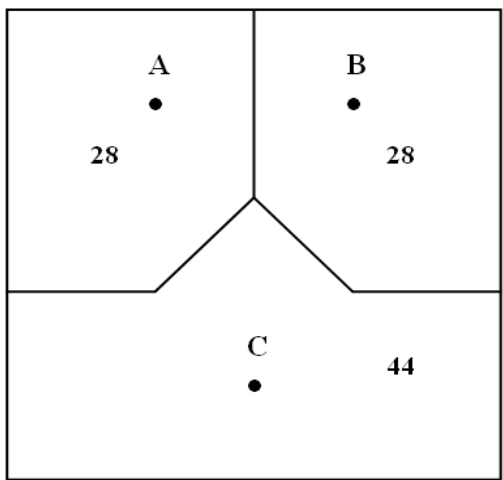

$1 \mathbf{a}$

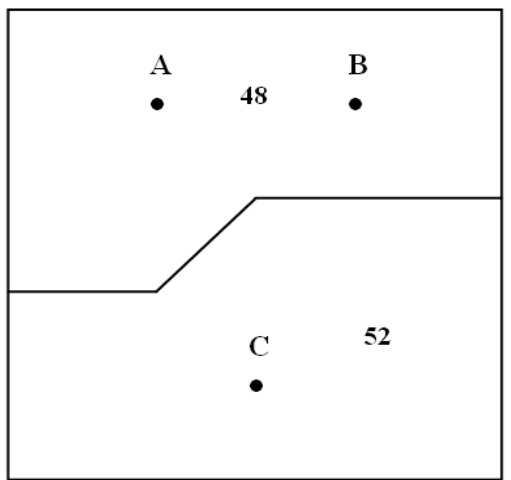

$1 \mathbf{b}$

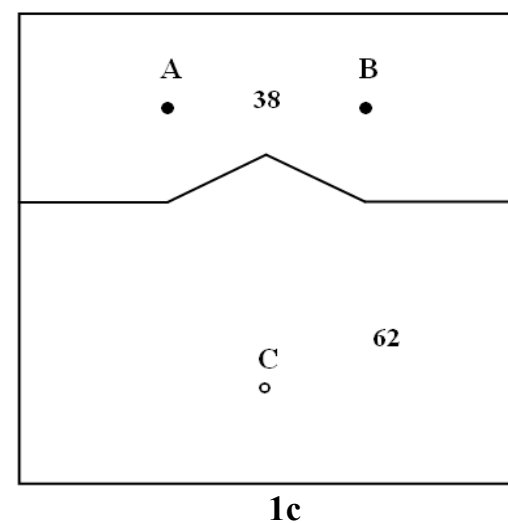

1c

Figure 1. Attraction basin of a three nodes scheme with a possibility of integration between $A$ and $B$

The scenario changes when $\mathrm{P}$ and $\mathrm{Q}$ come into multipurpose complementarity. In this case the user that buys product $\mathrm{P}$ in $\mathrm{A}$ must go to $\mathrm{B}$ for the product $\mathrm{Q}$. Alternatively he may go to $\mathrm{C}$, and then he has an incentive to acquire both $\mathrm{P}$ and Q, dropping A.

Analyzing the total road distance, an unbalanced attraction basin is obtained. In both cases the new basin of $\mathrm{C}$ grows in comparison to the two basins separated. The figures labelled sub c) in each row show the new situation, and it is easy to check that the more the distance between $\mathrm{A}$ and $\mathrm{B}$, the more the attraction loss of the complex $\mathrm{AB}$ becomes marked. In the first case it has the distribution 38 in $\mathrm{AB}, 62$ in $\mathrm{C}$, still quite balanced, but in the second case the basin of attraction of $\mathrm{AB}$ splits into two parts and records the value of 16 against 84, definitely not economically viable.

The flexibility of the functions is preferable to specialization that requires very large catchment areas, and networks have made possible many combinations of functions. A macroeconomic analysis of the situation in the European Union, including hotels, restaurants and leisure has been performed by two of the authors, who in [5] have considered the effects of diversification, while in [6] they have dealt with the effects of vertical integration (that can be considered somehow an aimed diversification).

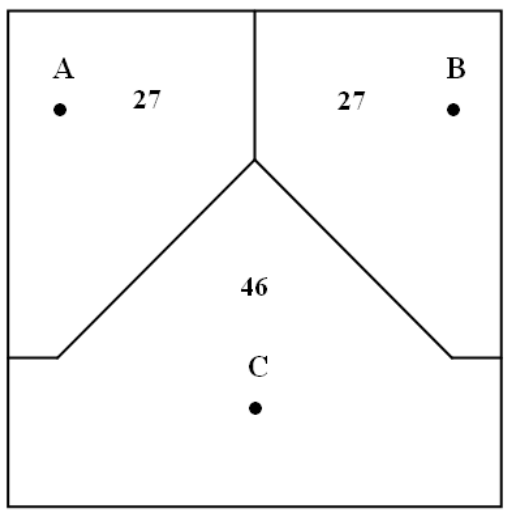

$2 \mathbf{a}$

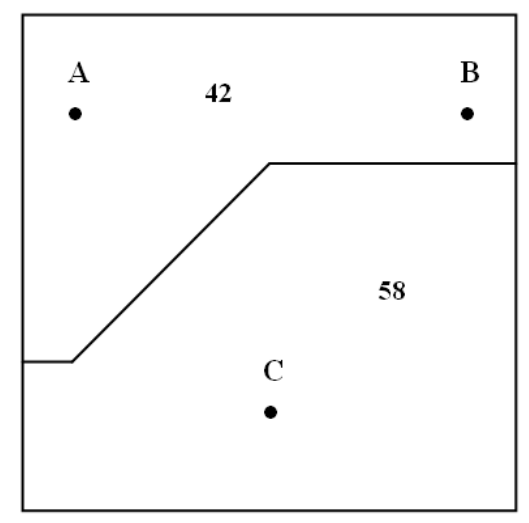

$2 \mathbf{b}$

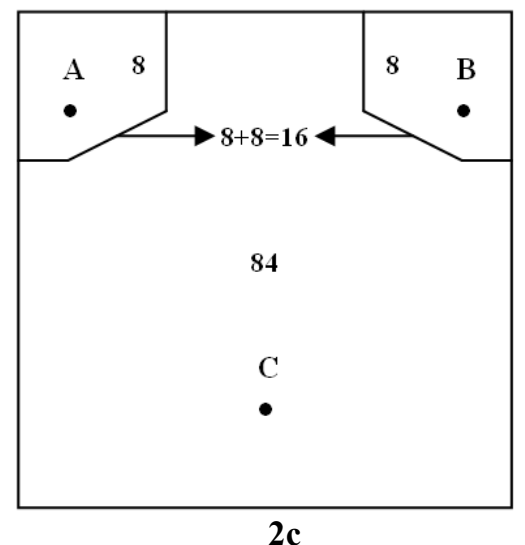

2c

Figure 2. Attraction basin of a three nodes scheme with no integration possibility between $A$ and $B$ 
Recalling some Italian cases related to communication and administration, we find state lottery offices (often supported at tobacconists) acting as certified paymasters for a variety of public duties, post offices that have extended the banking function. On the deconstructive side, network communications have reduced the weight of mail, and now electronic certifications are reducing the role of registered mail. The reduction of the need for an exterior certification is spreading to banks through home banking. In general the tendency of many high level services is to shift towards virtual systems.

The problem also arises for goods related to the use of the landscape-cultural mosaic, both in terms of minor art centers, and in terms of resorts. Sometimes promising initiatives decade because they cannot achieve economic viability, which often should come from a multipurpose offer and therefore requires at least the insertion in a circuit easy to follow. Isolated monuments, isolated sporting facilities may hold only if they are world wide known emerging marks and are supported by appropriate complementary goods (restaurants, campsites, hotels, documentation centers, shops, etc.). Generally a strategy of vast area is required, which in turn needs efficient and well integrated means of transport to reduce environmental negative impacts.

Another appealing solution is space-time concentration. A well-publicized temporary exhibition usually allows to achieve economic sustainability, although purists often complain about the failure of stimulating niche exhibitions, that should have the utmost scientific and cultural value, but are less attractive for the majority of people.

\section{Objectivity and subjectivity of time and distance}

Up to this point the determination of distances was not considered. The problem may be very different depending on whether physical distances or virtual distances on networks are considered. In the case of physical distances there are three attributes: metric distance, travel time, cost of travel. The search for the minimum distance between two physical locations becomes a problem of multiobjective optimization. The weights and constraints to be assigned to the various attributes, however, depend on the needs of the particular user and on the actual means which he/she may use at that moment, hence "distance" has always some subjectivity.

Consider now the time, as the most significant distance in contemporary life. For each pair of nodes (locations) such that a direct comunication exists the minimum connection time can be assigned. On this basis a table of minimum distances between every couple of nodes using both direct and composed paths can be built (See in [8] Djiskra's and Floyd's algorithms). The historical evolution of the table mainly leads to the reduction of its values, but this rule does not hold in general, even in the long term (50 or 100 years). It has gone down from maxima of some months to maxima of the order of 48 hours. These 
maxima in theory might even fall further if all constraints of cost and/or authorization are removed, using military aircraft. On the contrary, time distances in the interior of the cities have increased in the last decades, with the exception of the construction of underground railways.

On this basis a map of isochronism can be constructed from any assigned location. It is a topographic map where the third dimension (level curves) rather than the physical height represent the temporal distance from the place of origin (which therefore is at zero level.) The "valleys" correspond to the fastest routes, the ridges that separate them correspond to locations accessible through branches, the "peaks" correspond to isolated areas with slower access time, such as urban centers closed to traffic. They look more and more like actual acropolis. The evolution over time has been to make the valleys (high-speed tracks) lower and lower and less pending; ridges (branches) in general have become more steep, while the acropolis, originally not very prominent, have become increasingly high and steep.

In the map of isochronism, the absolute minimum lies at the point of departure. Are there points of relative minimum? Until the means of transport must physically pass through the territory and each point is appropriate to stop, minima do not exist, because each path runs along a geodesic, i.e. a curve of minimal distance (temporal, in this case), and then each intermediate locality along the geodesic lies at a lower level than the endpoint.

For each value of time $\mathrm{T}$ a hypocronic set, $\mathrm{E}(\mathrm{T})$, is defined as the set of locations reachable in time $\mathrm{t} \leq \mathrm{T}$. Obviously, the origin belongs to all the hypocronic sets. Another property is the obvious inclusion: if $\mathrm{S}<\mathrm{T}$, then $\mathrm{E}(\mathrm{S}) \subseteq$ $\mathrm{E}(\mathrm{T})$.

It holds the following important connection property: If there are no points of local minimum different from the origin, all the hypocronic sets are connected.

In this case the geodesic path connecting two nodes passing through the area is monotonously increasing. Scenario changes dramatically when there exist privileged nodes that are reached without touching the places in between (airlines), or without access to the places encountered as in the case of railways and motorways. There is a shift towards virtual nets, where only nodes and interconnections count.

Figure 3 shows a linear section in which coexist a rapid vehicle (plane) which connects $\mathrm{A}$ and $\mathrm{E}$ in 2 hours without intermediate stops, a fast vehicle (train) which connects $\mathrm{A}, \mathrm{B}, \mathrm{C}, \mathrm{D}$ and $\mathrm{E}$ in 8 hours and a local vehicle (bus) that connects all the points of the path in 16 hours. In figure $3 \mathrm{a}$ ) it is supposed that one has to wait an hour to find a train back to D. In figure $3 b$ ) there is a 2 hours delay before getting both train and plane, but there are no delays in the connections. The temporal distance function is the one indicated in the figures, and the local minima in all the cities where the train stops can be remarked. The two figures show examples of connection through exchange nodes, but also point out the weight of intermodality when synchrony is lacking. 


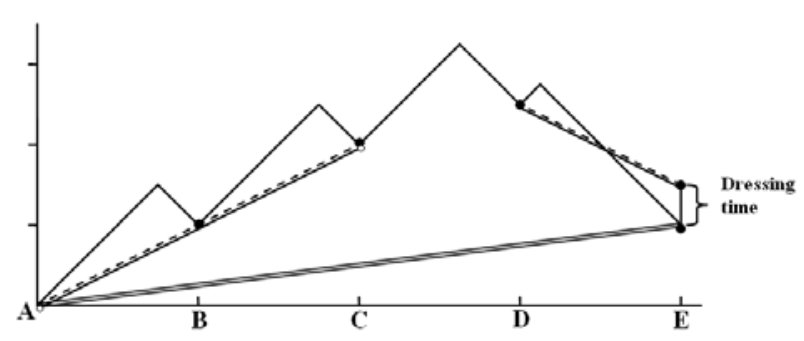

3a

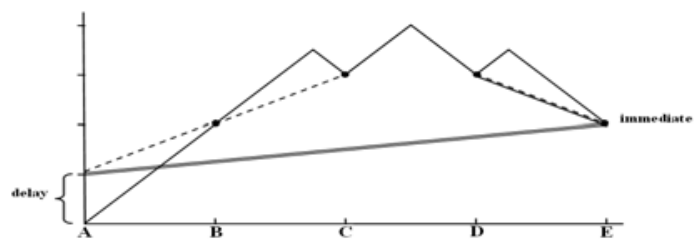

3b

\section{Air \\ Bus \\ Train \\ Figure 3. Isochrony along a geodetic where the connection jumps between different cities (plane and train).}

From the point of view of the individual, the time required to travel along a multipurpose trip is usually longer, since it requires a greater intermodality, with the delays that it involves; periurban congestion is hardly overcome by public transport, especially in Italy where the construction of underground lines is in arrears. Furthermore, the net of public transport not always has the necessary level of capillarity. The multipurpose trip is very different for the city dweller and the tourist. The car use, appropriate for a neighborhoods visit, is generally incompatible with the urban visit. The park and ride is a good solution, but often the timing is not satisfactory due to the deficiency of infrastructures and information. The city dweller vice versa can often optimize the matching functions to be satisfied, distinguishing the multipurpose trip to be made by public transport from those appropriate for private means.

\section{Conclusions}

Telecommunication techniques, with flexibility and ubiquity, allow to transmit a lot of information specifically targeted to the user's interests. In a smart city one can receive information about traffic, waiting times for public transport, availability of parking. This allows an optimal decision strategy, both at the individual and at the supervised level. The question arises whether the smart city does not reduce the appeal of the discovery of a new place, deciding for us and eliminating all those unforeseen events which make an exploration memorable, as we learn from environmental psychology. Uncertainty reduction can be appreciated, what is annoying is the excess of documentation and comparisons. In this way the actual presence in the museum or exhibition is replaced by a virtual classroom, so that being in person on the spot tends to become a purely statistical fact that prevents the emotion tied to initiation. The demystification, which began two centuries ago when tourist guidebooks spread out, is now 
exasperated and transforms our emotions in cold awareness ${ }^{17}$. Therefore, we must reclaim the mystery and surprise of exploration, following Kaplan's ([12]) established pattern of environmental psychology, which suggests the following sequence of predictors for environmental pleasantness.

Table 1

\section{Kaplan's predictors ${ }^{18}$}

\begin{tabular}{|l|l|l|}
\hline & Understanding & Exploration \\
\hline Immediate & Consistency & Complexity \\
\hline Deferred & Readability & Mystery \\
\hline
\end{tabular}

\section{Summary}

Christaller's venerable theory of central places is a milestone for any territorial analysis (section 1). The combination of the various types of service give rise to the centrality and its presence is necessary, even in the most modern forms such as edge cities (section 2). The central point of the analysis relies on the concept of multipurpose trip and on the consequent ways of exploring networks; it is compared with theoretical models developed by computer science and theories of cognitive maps that mediate the extreme theoretical models, fitting into the modern theory of random networks (Section 3). There is a clear secular trend to simplification of the system of central places, eliminating many low-ranking centers to concentrate in the chaotic dominant centers (Section 4). The construction of the distances map, both physical and informative, overcomes the simple geometry; the geodesic structure has changed over the past fifty years, and becomes subjective, separating the dweller and the visitor (section 5). A final question: will smart city make more functional the use of the city? Will make it more challenging and more enjoyable?

Acknowledgement: the Authors greatly appreciated M. Yassin for his valuable comments and suggestions

\section{Bibliography}

1. Beavon, K.S.O. (1977). Central Place Theory: A Reinterpretation. Longman.

2. Becker, G.S. (1965). A Theory of the Allocation of Time. Economic Journal 75, 493-508.

3. Berry, B.J.L. \& al. (1988). Market Centers and Retail Location. Prentice Hall.

4. Calvino, I. (1972). Le città invisibili. Torino: Einaudi.

5. Chang, T.F.M.; \& Iseppi, L. (2011). Specialization versus Diversification in EU Economies: a Challenge for Agro-food? Transition Studies Review, Vol. 18, n. 2, 16-37.

6. Chang, T.F.M.; \& Iseppi, L. (2012). EU Agro-Food Chain and Vertical Integration

\footnotetext{
${ }^{17}$ A thorough discussion was made by two of the authors in [14].

${ }^{18}$ The two columns represent two steps of the environment knowledge: understanding is the attempt to give a sense and exploration is the attempt to deepen its knowledge. The first horizontal row is related to the possibility of perceiving certain aspects of the environment immediately, the second refers to what may be inferred later.
} 
Potentiality: a Strategy for Diversification? Transition Studies Review, Vol. 19, n. 1, 107-130.

7. Christaller, W. (1933). Die zentralen Orte in Sueddeutschland. Jena, Fischer Verlag.

8. Cormen, T.H.; \& Laiserson, C.E.; \& Rivest, R.L. (1990). Introduction to Algorithms. New York: Mc Graw Hill.

9. Garreau, J. (1991). Edge City: Life on the New Frontier. New York: Doubleday.

10. Herbert, D.T., Thomas, C.J. (1982). Urban Geography - A first Approach. John Wiley \& Sons.

11. Hotelling, H. (1929). Stability in competition. Economic Journal 39, 41-57.

12. Kaplan, R. (1977). Patterns of environmental preference. Environment and Behavior, 9, 195-216.

13. Lefebvre, C. (1999). Sviluppo regionale e reti di città. Milano: Franco Angeli.

14. Piccinini, L.C., Chang, T.F.M. (2011). Radici psicologiche e intellettuali del Wonderland: dalla Wunderkammer alle Disneyland del mondo attuale. Architettura del Paesaggio, Overview Vol. 24.

15. Piccinini, L.C., Chang, T.F.M., Taverna, M. (2000). La scelta residenziale nelle aree periurbane tra benessere e libertà. Agribusiness Paesaggio \& Ambiente, 4, 198-213.

16. Piccinini, L.C., Chang, T.F.M., Taverna, M. (2011). Dimensione, percezione ed esplorazione del Wonderland. Agribusiness Paesaggio \& Ambiente, 14, 100-108.

17. Sylos Labini, P. (1982). Oligopolio e progresso tecnico. Torino: Einaudi.

18. Tubaro, G.,Piccinini, L.C., Iseppi, L., Serafino, L. (2006). Preservazione della centralità nelle aree montane e rurali. Agribusiness Paesaggio \& Ambiente, 9, 11-24.

\begin{tabular}{|r|l|}
\hline Mario Taverna & $\begin{array}{l}\text { Department of Civil Engineering } \\
\text { and Architecture } \\
\text { University of Udine } \\
\text { E-mail: taverna@uniud.it }\end{array}$ \\
\hline Livio C. Piccinini & $\begin{array}{l}\text { Department of Civil Engineering } \\
\text { and Architecture } \\
\text { University of Udine } \\
\text { E-mail: piccinini@uniud.it }\end{array}$ \\
\hline Ting Fa Margherita & $\begin{array}{l}\text { Department of Civil Engineering } \\
\text { and Architecture }\end{array}$ \\
Chang & $\begin{array}{l}\text { University of Udine } \\
\text { E-mail: chang@uniud.it }\end{array}$ \\
\hline Luca Iseppi & $\begin{array}{l}\text { Department of Civil Engineering } \\
\text { and Architecture }\end{array}$ \\
& $\begin{array}{l}\text { University of Udine } \\
\text { E-mail: iseppi@uniud.it }\end{array}$ \\
\hline
\end{tabular}

